\title{
EN TORNO A LA SÁTIRA 5 DEL LIBRO II DE HORACIO
}

Norma Porto de Farías

Como correctivo ético y social, las Sátiras de Horacio se inscriben en el ideal latino ridendo castigat mores (1), castigar costumbres riendo; como género literario, plasman la expresa intención del autor del cuidado y equilibrio formales.

En la literatura occidental, desde la antigüedad grecolatina hasta la actualidad, lo satírico unido a lo cómico, sigue teniendo la función de rechazo de anormalidades de la sociedad, de denuncia, para imponer sobre los vicios, el caos o el absurdo, un orden. Dentro de este marco, la lección ejemplificadora de Horacio consiste en su humanismo, en saber manejar la ironía con fineza, sin caer en el sarcasmo para no lastimar.

El poeta venusino, satirista reflexivo y observador agudo, hace desfilar en sus Sátiras a tipos característicos de la sociedad romana de su tiempo con rasgos caricaturescos. Su pintura de la disgregación del cuerpo social por conductas individuales viciosas o corruptas no se hace desde la óptica pesimista que muestra una época en decadencia, sino desde la perspectiva del creador que adhiere y participa en la construcción de un nuevo orden político y moral preconizado por el Príncipe Augusto y su ministro Mecenas. Éste es el espíritu que anima la composición total de sus Sermones, Conversaciones, tal el título que dio el propio autor a su obra. Junto a la mordacidad y la risa encontramos tiernas escenas autobiográficas de reconocimiento a la figura paterna, manifestaciones de sincera amistad a Mecenas, el elogio de la tranquilidad de la vida campesina, o la expresión de la humana sabiduria de la vida del parvo vivere, vivir con poco.

En la misma obra, Horacio expresa y aplica su propia teoría literaria: la burla y el lenguaje coloquial no excluyen el cuidado del estilo. El justo medio en la vida y en el arte. "No es bastante dislocar las mandibulas del oyente a fuerza de risas. En esto, sin embargo, hav también cierto mérito. Hace falta brevedad para que fluva ágil el discurso $v$ las orejas de los oyentes no se cansen y aquél no se trabe con palabras pesadas. Pero hace falta un lenguaje serio, unas veces, $y$, con frecuencia alegre que defienda en ocasiones el estilo del orador o del poeta. $Y$ a veces, el del ciudadano educado que ahorra sus fuerzas o de propio intento las gasta. Lo ridiculo dirime en muchas ocasiones grandes controversias con más fuerza $v$ mejor que las severas expresiones" (2). Más adelante agrega: "Cuando vavas a escribir, da vuelta muchas veces el estilo y no te afanes en que te admire la masa." (3)

La Sátira II, 5 es una muestra acabada de que Horacio es fiel a sus propios preceptos. La crítica a la psicología del arribismo y a la filosofia del "ser por el tener" tiene el soporte de la parodia que junta la gracia con la fuerza de la ironía para entregarnos un regocijado boceto de un tipo social inescrupuloso como el del "buscador de herencias". Temáticamente, satiriza a aquellos que utilizan métodos espurios para enriquecerse, 
representado por un personaje típico de la época "el captador de testamentos", una más de làs tantas artimañas para el enriquecimiento ilícito. Cicerón en De officiis III, 74, denuncia la práctica frecuente en el mundo romano de la industria de los captadores de testamento, posible por el número creciente de ricos solteros. Formalmente, es un diálogo entre Ulises y Tiresias in inferiis, en el mundo de los muertos, que se presenta directamente sin ninguna voz narradora ni indicación escénica. La apertura ex abrupto de la conversación produce el efecto deseado: predispone al lector a introducirse en la realidad hondamente significativa de las katábasts épicas, pero prontamente se encuentra con guiños e indicios que implican la inversión de los valores sustentados por el mundo heroico.

La sátira parodia un pasaje de la Odisea, "la consulta a los muertos", y su tono burlón e irónico surge del contraste entre el ámbito homérico-mitológico donde se ubican sus personajes y la descripción de una sociedad romana corrupta revelada en el motivo de dicha consulta artibus atque modis, artes y medios para enriquecerse. El momento es descripto como contemporáneo; y el medio ambiente, el de las instituciones, y cultos romanos.

La sátira se compone de 110 hexámetros. El verso inicial repite el esquema del poema griego: una vez terminado el vaticinio de Tiresias que anuncia a Ulises su regreso a Ítaca además de pronosticarle una larga vida, el héroe pide le dé las claves para poder hablar con su madre muerta: pero ahora pon mente a mi ruego y explica esto otro. (Odisea, XI, v.140). Una fórmula semejante utiliza Horacio en el primer verso que se encabalga con el segundo: También esto. Tiresias, además de lo narrado, al que te ruega, responde. La diferencia está en la ampliación de la consulta: el deseo de comunicarse con su madre en el poema griego; los medios para reparar la fortuna perdida, en la sátira romana. Tiresias responde con un gesto de risa. Esa actitud de viejo vate es inadecuada en el mundo subterráneo donde se encuentran, pero obedece al extrañamiento de la pregunta. Se establece así un claro contraste entre el cuadro homérico origina' y su recreación latina de donde deriva la ironía satírica: la imagen del adivino presentada en un ámbito ritual solemne con cetro de oro bebiendo negra sangre de una fosa, acto mágico que separa el espacio profano del sagrado, por una parte; y Tiresias riendo, por otra.

Horacio mantiene la caracterización de Ulises como el astuto y trata de imitar el estilo de la epopeya utilizando el epíteto: dolosus. Pero las artes y los ardides, que le habían servido al héroe para salvar su vida y la de sus compañeros de tantos peligros como el de los cíclopes o las sirenas, deberán ser aplicadas esta vez a objetivos menos nobles convirtiendo a Ulises en un ser vil e indigno totalmente alejado del personaje de la tradición. La degradación del héroe es paulatina. El tono de lamento por su propia suerte de hombre empobrecido que imprime a su petición, desdibuja la figura heroica. El estilo reproduce esa lamentación a través de los recursos de enumeración en gradación y de la aliteración: 
Núdus inópsque domúm redeám, te uáte, neque illic áut apothéca procís intácta est aut pecus; átqui ét genus ét uirtús, nisi cúm re, uílior álga est

(versos 6-8)

desnudo y pobre vuelvo a casa, tú lo has vaticinado, y allí ni la bodega ni el rebaño fueron dejados intactos por los pretendientes (de mi mujer); y el linaje y la virtud, si no es con riquezas, son más viles que un alga.

La conclusión nos remite, por una parte, al planteo inicial de la Sátìra $\mathbf{I}, 1$ el hombre en una sociedad descompuesta vale por lo que posee y no por lo que es; y por otra, descontextualiza el discurso ya que el núcleo de valores que expresa son propios del romano de su época y no del ambiente épico.

Los consejos del profeta, que se dan en un tono invariable punzante y cínico, pero suelto y sin retórica de acuerdo con el nivel coloquial del lenguaje, en coincidencia con la actitud del peticionante (missis ambagibus, dejadas de lado las ambigüedades, sin rodeos) y en discordancia con el lenguaje sibilítico, describen las prácticas corruptas de los cazadores de herencia, particularmente la de aquellos ricos sin descendencia.

El anuncio detalla estrategias y tácticas infames salpicadas con picarescas anécdotas. Se da en núcleos de intensidad creciente:

1. V.11 al 19: Adulación a un anciano rico sin que interese su condición moral.

2. V.20 al 26: La perseverancia en el acecho aun después de un fracaso.

3. V.27 al 44: Posibilidad de hallar una nueva víctima en un litigio judicial en el foro

4. V.45 al 69: Arte de seducir a un viudo que cría un hijo enfermo,

5. V.70 al 83: Métodos de asedio a través de la lisonja a los criados o a la mujer de un viejo necio.

6. V.84 al 88: Anécdota ilustrativa.

7. V.89 al 109: Nuevas estrategias de asechanza directa.

8. V. 110: Final ex abrupto, Proserpina arrebata al agorero.

En el primer núcleo, el cousejo todavía está envuelto en cierto tono oracular por la presencia de un tordo que volará a indicarle el brillo de la fortuna, una especie de talismán sagrado, un augurio feliz que se opone a la irreverencia de la propuesta que profana hasta a los mismos dioses ya que antes de los deberes sacros está la veneración al viejo rico. Se imita un gesto ritual degradándolo totalmente. La imagen de la ofrenda tiene vuelo lírico. Se presenta así una doble inadecuación: el tono sibilítico, el ambiente ritual y el lenguaje lírico - la propuesta indecente de su mensaje; el ámbito infernal griego - el culto romano al dios Lar. Horacio se regocija jugando con un complicado contexto de supuestos lingüísticos y sociales.

La reacción inicial de Ulises muestra una punta del orgullo del héroe, orgullo que se va desvaneciendo poco a poco por la contudencia de los juicios de Tiresias. Ante la 
proposición de formar el cortejo del viejo rico como escolta yendo del lado que corresponde al esclavo, el héroe se siente humillado y se niega a mostrarse en público de esa manera. ; cómo! ¿Quieres acaso que yo cubra el lado de aquel puerco de Dama? No obraba yo de esa manera en Troya, donde siempre competía con los mejores, protesta, pero la conclusión del adivino es tan terminante, ergo pauper eris, por lo tanto pobre serás, (v.19-20) que Ulises rápidamente cambia de opinión. El ingenio zumbón de Horacio crea un personaje voluble, la protesta surge recién cuando se le sugiere que la lisonja quede expuesta públicamente; lo que deja inferir que lo molesto no es la posibilidad del envilecimiento, sino que su indecencia quede al descubierto ante los ojos de los demás. Horacio se mofa de la hipocresía social que valora la máscara del parecer sin importar las convicciones profundas.

Así como en el comienzo un gesto: ¿De qué ríes? bastó para introducirnos en un clima de chanza y establecer la ruptura de niveles, aquí el laconismo de la respuesta: Por to tanto pobre serás, que contrasta con el resto de los largos parlamentos del mismo personaje excesivamente locuaz, genera un cambio de actitud en el interlocutor. Estilísticamente, la estructura compositiva de los versos 19 y 20 señala la precipitada ligazón de argumento y efecto: la visión de la pobreza es el más firme fundamento, la argumentación más persuasiva para promover una rápida metamorfosis: Ulises está dispuesto a hacer cualquier cosa con tal de obtener bienes. El autor se burla, en su recreación, del personaje y del tipo social oportunista, inclinado a cualquier bajeza con tal de enriquecerse

\footnotetext{
"Mé gessí, certáns, sempér melióribus."

$\begin{array}{ccc} & \text { "Érgo } & 19 \\ \text { páuper eris. } & \text { "Fortem hóc animúm toleráre iubébo } & 20\end{array}$

"No obraba yo (de esa manera en Troya) donde siempre competía con los mejores."

"Por lo tanto pobre serás".

"Puesto que así será yo obligaré a mi espiritu fuerte a tolerarlo".
}

La cesura del verso 19 permite el cambio de interlocutor y deja en suspenso la conjunción consecutiva ergo, por lo tanto, que se resuelve brevemente en el verso siguiente páuper eris. pobre serás. Una nueva cesura en el verso 20 coincidente con la acentuación final aguda (páuperis) marca la rápida decisión de Ulises, yo obligaré a mi espiritu fuerte a tolerarlo. Argumentación y consecuencia se dan en estrecha simbiosis no sólo en el plano semántico sino también en el plano estructural del verso. La sonoridad lograda por la aliteración, la acentuación y la sinalefa fortóc, imita el sonido de un cuerpo que se resiste a los golpes. Todo este cuidado estilístico está puesto en función de provocar sonrisas. La contestación de Ulises es más propia de una sentencia moral que de la expresión del sentimiento villano y ruin aqui manifestado. 
Los versos 21 y 22 con los que concluye este núcleo pintan en un cuadro jocoso a un héroe totalmente convencido, ansioso por conseguir la fortuna en forma rápida y a cualquier precio, en una postura de aventurero pirata dispuesto al asalto. Di pronto- protinus-, aguijonea Ulises, unde ruam- desde dónde me lanzaré a la riqueza y a montones de bronce. La arquitertura del verso refuerza el sentido con un precipitarse de sonidos guturales:

Tu prótinus únde

diuitiás aerisque ruám, dic, áugur, acéruos

La posición central de ruám, me precipitaré, irradia el sentido a toda la unidad oracional

El segundo núcleo, de transición, aconseja la perseverancia en el acecho sin olvidar que debe ser realizado con ingenio conforme a la personalidad del héroe.

El núcleo tercero es un cuadro escénico de color bien romano, perfectamente imbricado en la estructura total, pero con factura independiente. Se desenvuelve en medio de un litigio en el foro. Tiresias le sugiere ofrecerse obsequiosamente como abogado de cualquier hombre rico y sin hijos sin que importe la justicia del caso. La escena, además de configurar un seguimiento de la caracterización del tipo principal, "el cazador de herencias", censura jocosamente la aplicación de la justicia. En el ámbito de un juicio civil, por el reclamo de bienes en este caso, se mueven actores particulares como aquellos que con tretas llevan a hombres honestos hasta los tribunales para litigar y quedarse con sus pertenencias, o los abogados que usufructúan el conocimiento de las leyes en su propio beneficio, defendiendo causas indignas, olvidando su verdadera función: la administración de la justicia:

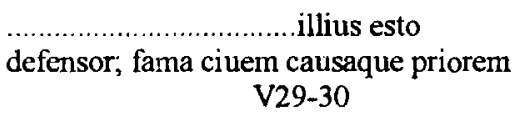

Defiende la parte de aquél, menosprecia al otro ciudadano aunque sea mejor en la opinión de todos y en la causa que litiga

Subsidiariamente se desprende de las versos 32 y 33 otro motivo de burla: las ansias de figuración social :

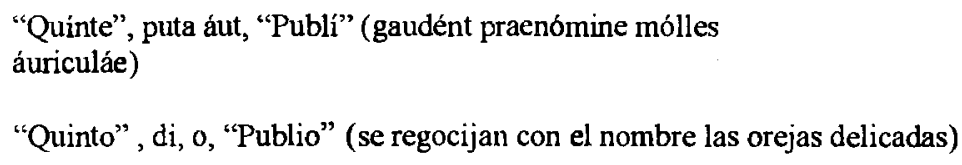


Los efectos sonoros del verso por la aliteración - cuin, pu,taut, pu, gau, qucrean la onomatopeya de un rumor zumbante, parecido a un aullido molesto, que imita el fastidioso parloteo de adulador. Introduce con estos versos el retrato mordaz del lisonjero obsecuente: "Persuádelo de que se vuetva a su casa y cuide bien su salud" (pelliculam curare, literalmente, cuidar su pielcita delicada). "Persevera y mantente obstinado". Los versos siguientes parodian satíricamente a un autor de epigramas, Furio Bibáculo. Repite una metáfora burda de este autor: hibernas cana nive conspuet Alpis, escupa a los Alpes invernales con cana nieve (v.41). El efecto humorístico se produce por un doble recurso, por la tosquedad del la metáfora y por la inadecuación del discurso lírico a un hecho vituperable.

Finaliza el cuadro con un juego teatral que deja imaginar un escenario replфto de curiosos que observan el juicio. Se capta una escena donde un asistente codea al litigante, gesto peculiar del chismoso, para murmurarle sobre la complaciente disposición de su defensor.

Horacio, después de mostrarnos este espectáculo, busca una nueva víctima. Tiresias dice a Ulises que persiga a algún viudo con un hijo enfermizo, y puntualiza socarronamente técnicas de acercamiento y seducción: llegar hasta el rico servil y suavemente para no despertar sospechas y conseguir que lo nombre heredero segundo. La concisión confiere a este pasaje una gran fuerza expresiva. Cuatro versos fueron suficientes para retratar al hombre rico, al inescrupuloso trepador y a una sociedad hipócrita que vive de apariencias. Con un solo rasgo nombra al opulento in re/ praeclara sublatus, altanero por una clara fortuna (v. 45). Junto a él crece un hijo enfermo, situación personal insuficiente para convertirlo en un ser más sensible y menos orgulloso. Su soberbia, sin embargo no le permite advertir las intenciones del oportunista que se le aproxima. Ne manifestum/ caelibis obsequium nudet te, para que tu franca obsequiosidad no te desnude ante el viudo (v.45-46), dice el vate. Horacio sugiere a través de su parlamento que en las relaciones sociales lo manifiesto es como una máscara que no descubre sino encubre los verdaderos propósitos. La parquedad con que. describe al arribista sintetiza una serie de connotaciones.

ádrepe-ófficiósus.......................
v. $47-48$
toma esperanzas y arrástrate hacia él servil y sigilosamente

Un adverbio (leniter, suavemente) y un adjetivo (officiosus, senvil) señalan 10 que se muestra, las actitudes; el verbo (adrepe, arrastrarse hacia, trepar hacia) indica lo que se esconde, intenciones. La posición de los términos en el verso sugiere gráficamente lo dicho anteriormente: leniter * adrepe *officiosus, suave y servilmente envuelven como en una coraza al verbo trepa. Lo exterior es una cubierta que esconde sentimientos y propósitos.

Los versos 50 al 55 se enlazan con los anteriores pues continúan los consejos para el arte de la simulación. Si alguien entregara al oportunista el testamento para leer, se le insinúa actuar con un doble discurso y con fingido desinterés. Ante la vista del testamento se presenta a un personaje de comedia: menea la cabeza en un gesto de negación, alarga los brazos 
para apartar de sí el escrito, pero estira el cuello tratando de reojo leer la linea donde en las escrituras se asientan los nombres de los herederos. El poeta, para darnos la conclusión de todo el pasaje, se remite a un personaje de fábula, la del cuervo codicioso engañado, demostrando su premisa con la presencia de oficiales del derecho corruptos, el escriba ex funcionario, que se aprovecha de su experiencia para embaucar a los demás, aun al astuto lisonjero. Esto le sirve de base para introducir la anécdota de Nasica y Corano que ilustra el tema del burlador burlado.

Son tan precisas las indicaciones del adivino que por hiperbólicas y detallistas producen la incomprensión del héroe:

"Num furis? An prudens ludis me obscura canendo?

v. 58

¿Acaso deliras? ¿O prudente te burlas de mi proponiéndome enigmas?

La respuesta disloca el discurso ya que vuelve a la textura usual de los poemas épicos y explica en tono de vaticinio una anécdota de disputa familiar por la dote y por la herencia entre suegro y yerno, Nasica y Corano, ubicando la acción en un tiempo contemporáneo romano, pero respetando las fórmulas y la solemnidad heroicas. "Tempore quo iuuenis Parthis horrendus, ab alto/ demissum genus Aenea", "En los mismos dias que un mozo, temido por los partos $y$ descendiente de la remota sangre de Eneas... " (v.62-63), la majestuosa introducción desarmoniza con el contenido del relato.

En el siguiente núcleo, Horacio vuelve a la descripción de nuevas argucias para atraer la voluntad de viejos ricos. Esta vez se fija en la figura de un anciano caduco e imbécil gobernado por su mujer o un liberto con quienes aconseja aliarse. Hay una gradación que va desde la insinuación del acuerdo con los seres despreciables que lo rodean hasta la adulación directa al propio anciano, pasaje que se introduce con una metáfora guerrera conforme a la imagen de asedio bélico que se desarrolla: sed uicit longe prius ipsum/ expugnare caput, pero lo más importante es asediar el centro mismo (v.73-74). La rastrera adulación llega a su climax cuando el adivino aconseja entregar al viejo mujeriego a la casta Penélope. El efecto satírico se logra con la respuesta de Ulises: ¿Por ventura, piensas que podrá ser llevada a tal irance una mujer tan retirada y casta a quien tanto galán y galanteador no pudieron desviarla del camino recto?(v.76-78) En realidad Ulises no rechaza totalmente la propuesta; lo detiene el hecho de que, según el vaticinio del mismo Tiresias, anunciado un momento antes acorde con la tradición homérica, Penélope es casta, púdica y de firme voluntad. En su respuesta el agorero degrada la figura de Penélope, símbolo de fidelidad, al sugerirle que la lealtad de su esposa se debía a que sus pretendientes eran grandes tacaños y que ninguno la había deslumbrado porque no la habían tentado con el obsequio de grandes riquezas. De aquí se clesprende otro subtema, la hipocresía humana en la prédica de la virtud. Se alcanza la virtud con voluntad de ejercerla, venciendo tentaciones y dificultades, y no por la falta de oportunidades para caer en un comportamiento ruin. En medio de una crisis social, todos tienen su precio inclusive Penélope u Odiseo. 
En el núcleo sexto cuenta una picaresca leyenda que pone en ridículo la tenacidad de los cazadores de herencia y su molesto asedio. Una astuta mujer había dejado expreso en su testamento como condición para que se cumpliera su voluntad, que el heredero, con la espalda desnuda y ungida de aceite, cargara su cadáver "Yo creo que, por si después de muerta podia desprenderse de él ya que de viva, no lo habla conseguido"(v.87-88).

El último núcleo concentra una infinidad de técnicas de acoso hasta el momento de la muerte del viejo cuando, según las insinuaciones del augur, será conveniente disfrazar los sentimientos de alegría con sollozos y dispensar pomposos funerales. Hay aceleración del ritmo en este final donde los consejos se suceden como en rápida catarata.

En el precipitado desenlace del verso 110 , vemos a Proserpina, imperiosa, arrebatar al adivino parloteador. Pareciera que la misma Diosa de los Infiernos, impaciente, no tolerara más la locuacidad irónica del habitante de su sagrado reino.

La sátira bucea con despiadada y obsesiva intensidad la inmoralidad de los cazadores de herencia, la que se acepta con irónica aprobación. Desde el punto de vista formal, concuerda con las consideraciones de estética literaria del propio autor quien al "delectare"deleitar-, une el "prodesse"- aprovechar. Cuando vayas a escribir, da vuelta muchas veces el estilo y no te afanes en que te admire la masa, dice Horacio. En efecto la parodia literaria que se construye sobre otro discurso, el homérico, requiere como primer paso la lectura de la Odisea y la reflexión sobre sus modalidades de expresión. El fragmento de la Sátira I,10 que anotáramos como síntesis de las reflexiones del autor sobre la creación literaria de la sátira, requiere del poema satírico concisión, pero al mismo tiempo variedad, por lo tanto diversidad en la unidad. La unidad está dada por el apoyo del lenguaje paródico , las realidad épica homérica en contraste con el marco cotidiano romano que tiene como trasfondo, $y$ el tono constante de burla orientado a la tipificación de un personaje peculiar: el cazador de testamentos. La variedad se asienta sobre el nivel temático y estilístico. A partir del tema principal, se desprenden temas tangenciales objetos de chanza: el enriquecimiento ilícito en general, la maledicencia y la murmuración, prácticas corruptas de abogados desleales y de otros funcionarios, el negocio de los juicios, la hipocresía social, dobleces del alma humana, el afán de mantener las apariencias, ansias de figuración social , valoración de la persona por su riqueza y no por sus virtudes, malos poetas. En plano estilístico, el lenguaje adquiere a veces vuelo lírico, a veces un tono solemne y la mayoría de las veces un nivel coloquial. Se suceden diferentes modos de presentación: retratos, cuadros con movimientos escénicos, relato de anécdotas y leyendas ilustrativas, la parodia dentro de la parodia, refranes populares y alusiones a fábulas, escenas mitológicas y cuadros extraídos de la realidad circundante. La fuerza expresiva surge algunas veces de la concisión de algunos cuadros; y otras, de largas tiradas como la que precipita el final donde se agolpan técnicas de asedio que crean la atmósfera de la presión del acoso y llega a un climax del cual se desprende un rápido desenlace. Los ex abrupto del comienzo y del final enmarcan toda la sátira. 
Afirma Wayne Booth "Las reconstrucciones de la ironia no se pueden reducir casi nunca, o nunca a gramática o a semántica o a lingüistica. Al leer cualquier ironía que valga la pena tener en cuenta, leemos la vida misma, y al abordarla nos basamos en nuestras relaciones con los demás. Leemos personajes y valores, hacemos referencias a nuestras más profundas convicciones."(4) En efecto, Horacio, en sus Sátiras, explora el comportamiento humano con ingenio zumbón y dibuja bocetos de la vida sin caer en sarcasmos hirientes o nihilistas. Nos entrega una filosofia de lo cotidiano en un juego de agudo humor.

\section{NOTAS}

1. Quamquam ridentem dicere verum/ quid uetat?, ¿aunque qué prohibe que diga la verdad riendo?. Sátira I,1, vs.24-25.

2. Horacio, Sátiras, $\mathbf{I , 1 0}$, vs. 7-15.

3. Ibidem, vs. $72-74$.

4. Booth. Wayne, Retórica de la Ironía, Madrid, Tecnos, 1986. 